\title{
Factors influencing chloride deposition in a coastal hilly area and application to chloride deposition mapping
}

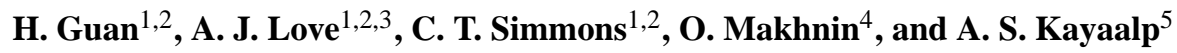 \\ ${ }^{1}$ School of the Environment, Flinders University, Australia \\ ${ }^{2}$ National Centre for Groundwater Research and Training, Australia \\ ${ }^{3}$ Department of Land, Water, and Biodiversity Conservation, South Australia \\ ${ }^{4}$ Department of Mathematics, New Mexico Institute of Mining and Technology, USA \\ ${ }^{5}$ Water Technology Division, Water Corporation, West Australia
}

Received: 20 July 2009 - Published in Hydrol. Earth Syst. Sci. Discuss.: 16 September 2009

Revised: 17 March 2010 - Accepted: 9 May 2010 - Published: 26 May 2010

\begin{abstract}
Chloride is commonly used as an environmental tracer for studying water flow and solute transport in the environment. It is especially useful for estimating groundwater recharge based on the commonly used chloride mass balance (CMB) method. Strong spatial variability in chloride deposition in coastal areas is one difficulty encountered in appropriately applying the method. A high-resolution bulk chloride deposition map in the coastal region is thus needed. The aim of this study is to construct a chloride deposition map in the Mount Lofty Ranges (MLR), a coastal hilly area of approximately $9000 \mathrm{~km}^{2}$ spatial extent in South Australia. We examined geographic (related to coastal distance), orographic, and atmospheric factors that may influence chloride deposition, using partial correlation and regression analyses. The results indicate that coastal distance, elevation, as well as terrain aspect and slope, appear to be significant factors controlling chloride deposition in the study area. Coastal distance accounts for $70 \%$ of spatial variability in bulk chloride deposition, with elevation, terrain aspect and slope an additional $15 \%$. The results are incorporated into a de-trended residual kriging model (ASOADeK) to produce a $1 \mathrm{~km} \times 1 \mathrm{~km}$ resolution bulk chloride deposition and concentration maps. The average uncertainty of the deposition map is about $20-30 \%$ in the western MLR, and 40-50\% in the eastern MLR. The maps will form a useful basis for examining catchment chloride balance for the $\mathrm{CMB}$ application in the study area.
\end{abstract}

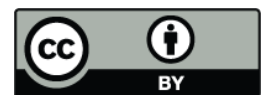

Correspondence to: H. Guan (huade.guan@flinders.edu.au)

\section{Introduction}

Chloride is one of the most commonly used environmental tracers for studying water flow and solute transport in surface water bodies (Dunn and Bacon, 2008; Shaw et al., 2008; Hrachowitz et al., 2009), vadose zones and aquifers (Eriksson and Khunakasem, 1969; Walker et al., 1991; Cook et al., 1992; Phillips, 1994; Wood and Sanford, 1995; Kirchner et al., 2000; Edmunds et al., 2002; Scanlon et al., 2002; Minor et al., 2007). It is particularly useful to estimate groundwater recharge based on chloride mass balance (CMB). The CMB method can be applied either for estimating point recharge with chloride concentration in the steady-state soil profile, or for estimating catchment-average recharge with chloride concentration in mean recharged groundwater (Wood, 1999). For situations where the atmospheric input is the only chloride source, and no chloride sinks exist in the system, the CMB method can be formulated as

$C_{\mathrm{p}} P=C_{\mathrm{g}} G+C_{\mathrm{r}} R$

where $C_{\mathrm{p}}$ is chloride concentration in bulk precipitation, $P$ is average precipitation, $C_{\mathrm{g}}$ is chloride concentration in groundwater that was recharged from the catchment, $G$ is groundwater recharge, $C_{\mathrm{r}}$ is chloride concentration in the runoff $R$. The CMB method does not require knowledge of detailed dynamic hydrological processes (although with such information, it would help to apply the CMB method more reliably). Thus, the method provides a good solution to estimate catchment groundwater recharge in mountainous terrains where hydrogeological and hydrometeorological conditions are complex (Wilson and Guan, 2004). In order to apply the CMB method, the atmospheric chloride input must

Published by Copernicus Publications on behalf of the European Geosciences Union. 
be known. In the inland area, atmospheric chloride deposition does not vary significantly over large distances (e.g., $\sim 100 \mathrm{~km}$ ) (Keywood et al., 1997). One estimate of average chloride deposition, either directly measured from bulk precipitation sampling, or indirectly inferred from the ratio of ${ }^{36} \mathrm{Cl} / \mathrm{Cl}$ which has a $30 \%$ uncertainty (Scanlon, 2000), is often used in the CMB calculation. In the coastal area, however, large spatial variability of chloride deposition is observed (Blackburn and McLeod, 1983; Keywood et al., 1997; Kayaalp, 2001; Biggs, 2006; Alcala and Custodio, 2008a). A detailed map of atmospheric chloride deposition in the coastal area is thus needed to apply the CMB method for estimating groundwater recharge.

It is commonly accepted that the primary source of the atmospheric chloride comes from the ocean. At the air-sea interface, the wind-induced whitecaps and bursts inject sea water drops into the atmosphere, forming sea salt aerosols (Lewis and Schwartz, 2004). About $10 \%$ of total chloride in the sea salt aerosols moves into the continents, and the majority of this chloride is deposited within $100 \mathrm{~km}$ of the coastal area (Eriksson, 1959, 1960). It should be noted that the anthropogenic sources may add chloride to the atmosphere at some extreme situations where serious air pollution occurs (Alcala and Custodio, 2008b). Two primary mechanisms, dry deposition and wet deposition, control chloride removal from the atmosphere to the land surface. Chloridebearing aerosols can settle down to the surface by gravitational forces. This dry deposition process is highly dependent on wind conditions and the aerosol size. Chloride in the aerosols can also be rained out from the cloud, or washed out by the falling rain drops. This wet deposition process is dependent on precipitation characteristics. In terms of hydrological applications, it is the total chloride deposition (bulk chloride deposition, or BCD hereafter), i.e., the sum of wet and dry depositions, that is important because it gives the input chloride for the CMB calculation (Wood and Sanford, 1995). Thus, BCD is usually measured from accumulated rain samples over a certain period, with samplers sitting in an open area, and exposed to the sky all the time. As chloride-bearing aerosols originate from the ocean, it is typically observed that BCD over the continents decays exponentially with increasing distance from the coast (coastal distance hereafter) (Keywood et al., 1997; Gustafsson and Larsson, 2000).

The function of coastal distance dependence, when quantitatively determined, is useful to estimate BCD for a point location at some known distance from the coast. However, two difficulties are encountered to directly apply this function in BCD mapping. First, the coastal distance-dependence reflects the efficiency of atmospheric chloride transport and how quickly it falls out or precipitates out. Therefore its parameterization may vary from place to place (Alcala et al., 2008a), which we term as the difficulty of function parameterization. Second, it is difficult to determine the coastal distance for each mapping pixel because this distance should be calculated from the coastal point that is upwind from the pixel. But this direction is often difficult to define. This problem is hereafter referred to as the difficulty of coastal distance quantification. Thus, geostatistical methods, such as kriging, are frequently used to map BCD. Carratala et al. (1998) performed ordinary kriging with 28 data points to construct a $10 \times 15 \mathrm{~km}^{2}$ resolution BCD map on the eastern coast of Spain. Gustafsson and Larsson (2000) applied ordinary block kriging to construct $10 \times 10 \mathrm{~km}^{2}$ resolution seasonal BCD maps with 49 data points over an area of $8 \times 10^{4} \mathrm{~km}^{2}$ in southern Sweden. Alcala and Custodio (2008a) used ordinary kriging to produce a $10 \times 10 \mathrm{~km}^{2}$ resolution mean annual BCD map with measurements at 200 geographic points for continental Spain $\left(5 \times 10^{5} \mathrm{~km}^{2}\right)$. For these mapping exercises, the ratio of data points over mapping pixels ranges from one 16 th to about one 60th. In the coastal area, BCD often varies significantly even over a few kilometres (Kayaalp, 2001). A BCD map of higher spatial resolution is needed, in particular, for the $\mathrm{CMB}$ application. The aim of this study is to construct BCD map at a spatial resolution of $1 \times 1 \mathrm{~km}^{2}$ over an area of $9000 \mathrm{~km}^{2}$, based on 17 data points. In contrast to earlier mapping studies, the ratio of data points over mapping pixels in this study is only one 500th. The sparse data points and small sample size largely increase uncertainty of the kriging estimates (Chang et al., 1998).

Can we incorporate some associated physical process information, including coastal distance dependence, to make more reliable estimates of chloride deposition to form a basis for BCD mapping? In this context, geostatistical approaches, such as residual kriging (RK), kriging with external drift (KED), and cokriging, can be used to incorporate information of secondary variables in the mapping (Isaaks and Srivastava, 1989; Goovaerts, 2000; Guan et al., 2005). Because it is difficult to incorporate multiple secondary variables in cokriging, RK and KED are considered in this study. For both methods, trend estimates are subtracted from the observations, before kriging is performed. The objectives of this study are first to examine the influencing factors associated with physical processes that control chloride deposition by correlation and regression analyses, and then based on this to construct a BCD map.

A number of factors can influence BCD. The first factor to be considered is the coastal distance. Two previously mentioned difficulties, one in function parameterization and the other in coastal distance quantification, need to be resolved to incorporate the coastal distance in the mapping. For the first difficulty, over a small area where the wind and precipitation climate is relatively simple, it is likely that one parameterization of coastal dependence function can be applied. In terms of the second difficulty, for simple coastal line geometry, the pixel geographical coordinates may be used as an approximate for coastal distance. As well as the commonly known coastal distance effect, topography may also influence BCD in the coastal area. For example, the relationship between elevation and BCD has been implicitly shown in Contreras et 


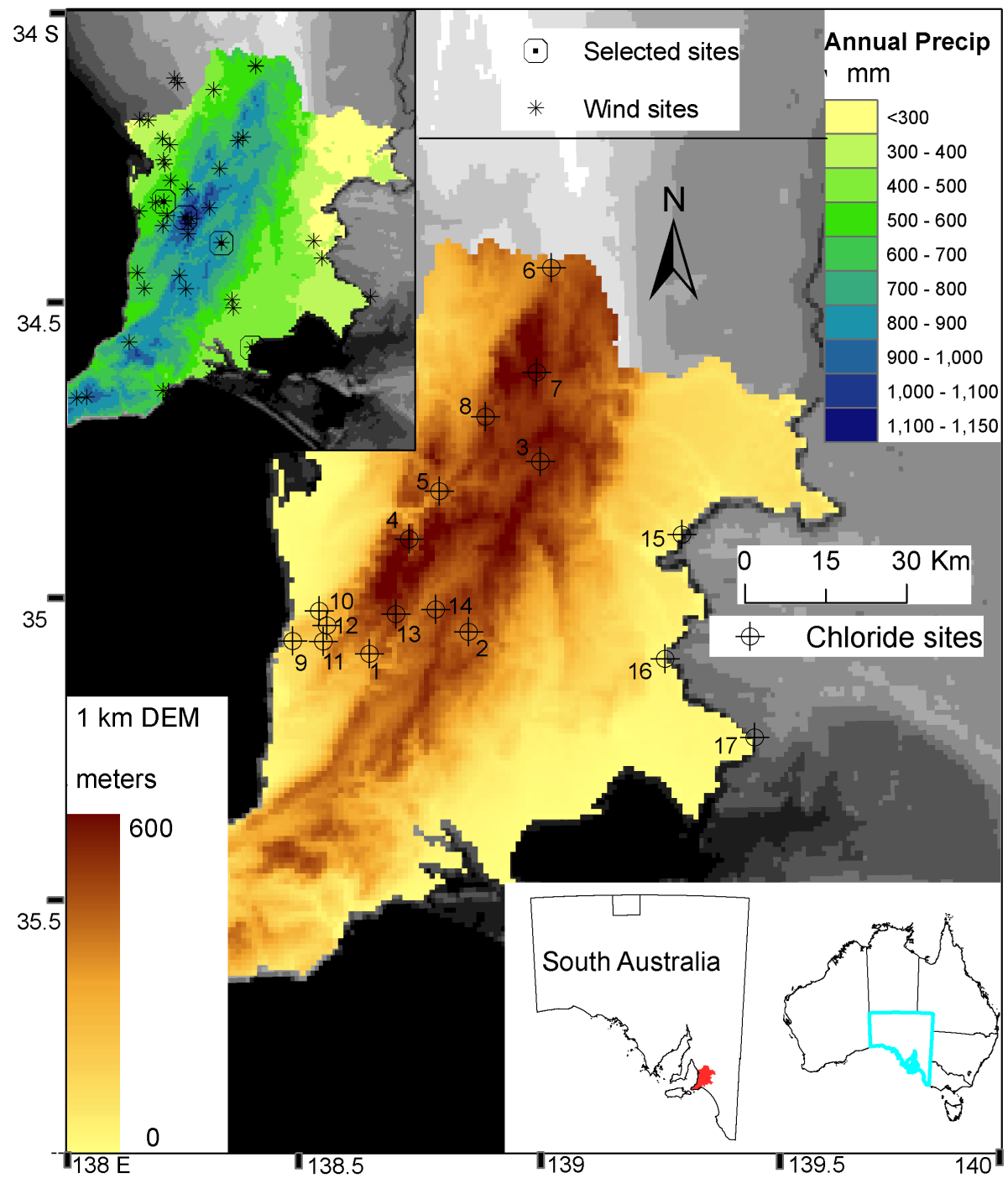

Fig. 1. The DEM map of the study area with 17 sampling sites (crossed circles) of bulk chloride deposition, with insert maps of Australia and South Australia showing the regional location of the study area, and an insert map of annual precipitation overlain by 41 wind observation sites (stars). The numbers next to the chloride sites correspond to those in Table 1. The Bureau of Meteorology IDs of the four selected wind sites (circled stars) from northwest to southeast are 23090 (W1), 23733 (W2), 23842 (W3), and 24545 (W4). The longitude and latitude marks are for the DEM map.

al. (2008). However, because elevation and coastal distance are highly correlated in their data, it is difficult to evaluate the relative importance of elevation effect. In this manuscript, we examine whether topography influences BCD by the removal of the coastal distance effect.

Our starting hypotheses are that in addition to coastal distance, (1) windward slopes, associated with sea breeze and in-coming moisture direction, enhance BCD due to topographic interception, and orographic precipitation, and (2) elevation enhances BCD due to increasing precipitation. The impact of vegetation canopy on BCD is not considered in this study because bulk chloride samples were collected in open areas. After the effective factors on BCD are identi- fied, they are incorporated into BCD mapping for the study area. The mapping results are compared to ordinary kriging and KED estimates, and cross validated with the observation data. The chloride map produced here will be used to examine the catchment chloride balance status, which is to be discussed in a subsequent manuscript.

\section{Methodology}

\subsection{Study area and data}

The study is based at Adelaide and the Mount Lofty Ranges (MLR) of South Australia (Fig. 1). The area has 1.2 million 
Table 1. Bulk chloride deposition and concentration over the Mount Lofty Ranges calculated from samples collected over two periods by DWLBC (1-8) and Flinders University (9-17), and associated site information.

\begin{tabular}{|c|c|c|c|c|c|c|c|c|c|c|c|}
\hline ID & Site id & Site name & $\begin{array}{l}\text { Easting } \\
(\mathrm{m})\end{array}$ & $\begin{array}{l}\text { Northing } \\
\text { (m) }\end{array}$ & $\begin{array}{l}\text { Elevation }^{\mathrm{a}} \\
(\mathrm{m})\end{array}$ & $\begin{array}{l}\text { Aspect }^{\mathrm{a}} \\
\left({ }^{\circ}\right)\end{array}$ & $\begin{array}{l}\text { Slope }^{\mathrm{a}} \\
\left({ }^{\circ}\right)\end{array}$ & $\begin{array}{l}\text { Precip. }^{b} \\
\text { (mm) }\end{array}$ & $\begin{array}{l}\text { Data period } \\
\mathrm{m} / \mathrm{y}-\mathrm{m} / \mathrm{y}\end{array}$ & $\begin{array}{l}\text { Concentration } \\
\quad\left(\mathrm{mg} \mathrm{l}^{-1}\right)\end{array}$ & $\begin{array}{c}\text { Deposition } \\
\left(\mathrm{g} \mathrm{m}^{-2} \mathrm{yr}^{-1}\right)\end{array}$ \\
\hline 1 & AW503502 & Scott Creek & 287895 & 6113235 & 272 & 256 & 0.08 & 751 & 02/03-02/05 & 5.4 & 4.05 \\
\hline 2 & AW426638 & Mount Barker & 306288 & 6117246 & 323 & 125 & 0.06 & 705 & $11 / 02-11 / 04$ & 6.1 & 4.63 \\
\hline 4 & AW504559 & Cherryville & 295316 & 6134505 & 531 & 295 & 0.10 & 1000 & 01/03-07/03 & 4.2 & 4.37 \\
\hline 5 & AW504563 & Milbrook & 300896 & 6143374 & 328 & 303 & 0.07 & 728 & 07/03-03/04 & 5.9 & 3.65 \\
\hline 6 & AW505517 & Penrice & 321661 & 6184765 & 314 & 306 & 0.03 & 557 & $12 / 03-11 / 04$ & 4.1 & 1.98 \\
\hline 9 & Kyp02 & Hallett Cove & 273701 & 6115600 & 125 & 279 & 0.09 & 654 & $04 / 92-12 / 94$ & 12.2 & 6.97 \\
\hline 10 & Kyp03 & Bedford Park & 278584 & 6121170 & 161 & 285 & 0.12 & 638 & 04/92-12/94 & 6.0 & 3.97 \\
\hline 11 & Кур04 & Happy Valley & 279315 & 6115516 & 149 & 272 & 0.11 & 692 & 06/92-11/94 & 4.9 & 3.78 \\
\hline 12 & Кур05 & Flagstaff Hill & 279991 & 6118507 & 180 & 278 & 0.12 & 714 & 06/92-12/94 & 6.5 & 5.10 \\
\hline 13 & Кур06 & Heathfield & 292858 & 6120585 & 414 & 251 & 0.06 & 983 & 07/92-12/94 & 4.7 & 4.76 \\
\hline 14 & Кур07 & Hahndorf & 300232 & 6121471 & 340 & 167 & 0.03 & 796 & 07/92-12/94 & 5.1 & 4.67 \\
\hline
\end{tabular}

a The elevation is 1-km pixel elevation, while aspect and slope are 9-km pixel values optimized in the regression.

$\mathrm{b}$ Precipitation is annual precipitation estimated based on long-term observations (Guan et al., 2009).

c This is weight mean bulk chloride concentration.

residents, with $60 \%$ of the water supply coming from the MLR. It covers an area of about $9000 \mathrm{~km}^{2}$, with a maximum topographic relief of $700 \mathrm{~m}$. The study area is bounded to the west by Gulf St Vincent, which extends $150 \mathrm{~km}$ in length and $70 \mathrm{~km}$ in width. To the south is the Southern Ocean, with Lake Alexandria (a fresh water lake influenced by sea water intrusion) on the southwest boundary of the area. The primary industries include health service, education, winery and agriculture. No obvious air pollution sources of chloride exist in the area. The bedrock in the MLR is late Precambrian metasedimentary rocks composed primarily of shales, siltstones, sandstones, and some limestone (Preiss, 1987). The climate is characterised by wet winters and dry summers. Annual precipitation ranges from below $300 \mathrm{~mm}$ to above $1000 \mathrm{~mm}$, with an areal average of $600 \mathrm{~mm}$ (Guan et al., 2009). Mean daily temperature over the area is $15-18^{\circ} \mathrm{C}$. The annual pan evaporation at a location of $600-\mathrm{mm}$ precipitation (area-average value) is about $1500 \mathrm{~mm}$ (BOM, 2009).

Bulk chloride concentration was measured at 17 sites in open areas, over two different periods by two organizations: Flinders University (1992-1994) and Department of Water, Land and Biodiversity Conservation (DWLBC) (20022005) (Table 1). DWLBC samples were integrated rain over multiple-month periods, while Flinders University samples were collected daily and summed to monthly. The DWLBC sampling followed the standard methodology of Friedman et al. (1992), where a thin layer of mineral oil was applied in the collectors to avoid water evaporation over the sampling period (although evaporation is not critical in measuring BCD).
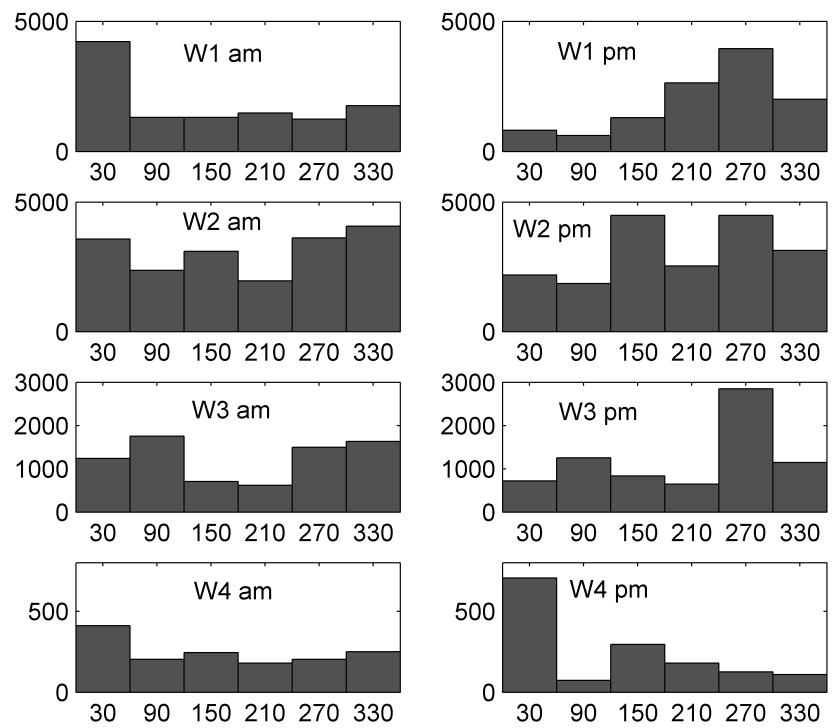

Fig. 2. Histograms of wind direction observed at 9:00 a.m. (left column) and 3:00 p.m. (right column) for four selected wind observation sites (W1, W2, W3, and W4 in Fig. 1). Horizontal axis shows bin centres of the wind direction in degree clockwise from the north. The data were collected by BOM in 1977-2008, 19572008, 1987-2008, and 1965-1969 for the four sites, respectively.

On average the sampling duration is about 2 years, with two sites (Sites 4 and 5) sampled for a period shorter than one year. They are nevertheless included because the sampling 
period covers both dry and rainy seasons. Both rain sample volume and chloride concentration were measured for each cumulative sample. Chloride concentration was measured with an ion chromatography system, with standard deviation of the repeating analysis being less than $0.1 \mathrm{mg} \mathrm{l}^{-1}$ over the normal sample concentration range. Average chloride concentrations and annual chloride deposition are calculated from samples at each of the 17 sites (Table 1). In addition, wind direction data for 41 sites in and near the study area were obtained from the Bureau of Meteorology of Australia (BOM) (Fig. 1). Wind direction was recorded twice daily at 9:00 a.m. and 3:00 p.m. local time.

It is relatively straightforward to quantify elevation, terrain aspect and slope for each sampling point. However, coastal distance needs to be quantified according to the direction of chloride aerosol sources. Prevailing westerly moisture flux feeds precipitation (Guan et al., 2009), and thus wet chloride deposition in the area. In term of dry chloride deposition, Gulf St Vincent to the west, and Southern Ocean to the south can provide marine aerosols to the study area. These two marine chloride sources can be brought into the study area by westerly winds and southerly winds, respectively. Westerly sea breezes occur frequently during part of the day (Figs. 2 and 7) over most of the study area, which fuel atmospheric transport of sea salt aerosols from Gulf St Vincent and facilitate dry deposition. In contrast, the southerly wind is not dominant in the study area, even at the southern edge (Fig. 2). Based on this understanding, for both wet and dry deposition trajectories, the dominant atmospheric chloride source in this area is from the west, i.e., from Gulf St Vincent by wind, and from a larger distance via atmospheric moisture transport into the area. The Southern Ocean may provide some additional atmospheric chloride source, but its effect is considered to be secondary. This assumption is supported by partial correlation results (Sect. 3.1). We use geographic coordinate $X$ (e.g. Universal Transverse Mercator, or UTM easting) to approximate the coastal distance for the chloride aerosols from the Gulf St Vincent source, and $Y$ (UTM northing) for chloride aerosols sourced from the Southern Ocean. Given the relative position of the study area with respect to the two marine aerosol sources, and the shape of coastal line (Fig. 1), this approximation is considered to be reasonable.

\subsection{Correlation analysis}

Correlation analysis has been widely used to examine the linear association between different variables. The Pearson product-moment correlation coefficient $(r)$ is the most common measure of linear association between two variables. When multiple variables are correlated to one another, the correlation coefficient of the variable of interest with any one of the other variables may give association implication which is not physically dependent. To solve this problem, a partial correlation coefficient is applied to examine the linear correlation between the two variables with the effects of other selected variables removed (Lowry, 1999-2009). An example of partial correlation coefficient between variables $x$ and $y$ independent of a third variable $(z)$ is calculated using

$r_{x y(z)}=\frac{r_{x y}-r_{x z} r_{y z}}{\sqrt{1-r_{x z}^{2}} \sqrt{1-r_{y z}^{2}}}$

where $r$ is Pearson correlation coefficient between the two variables denoted in the subscripts. The partial correlation coefficients are calculated with MATLAB in this study. After $r_{x y(z)}$ is obtained, the significance is tested with a tdistribution. The $\mathrm{t}$-value is calculated by

$t=\frac{r_{x y(z)}}{\sqrt{\left(1-r_{x y(z)}^{2}\right) /(N-2)}}$

where $N(\geq 6)$ is the number of samples (Lowry, 1999-2009). Strictly speaking, the significance testing relies on the assumption that each variable is spatially independent, which is often invalid for regionalized random variables, such as the ones examined here. Thus, the p-value of each correlation coefficient, based on t-testing is not strictly correct. Nevertheless, they should be still useful to compare which variables are more important to bulk chloride deposition, and to determine which variables are not significant (details are discussed in the Results section). This loose significance test is applied to examine our two hypotheses, one relating to the elevation effect and the other associated with terrain aspect (slope orientation) effect on BCD. If the tested factor is important to $\mathrm{BCD}$, the partial correlation coefficient between $\mathrm{BCD}$ and the factor variable should have a corresponding $\mathrm{p}$ value much smaller than others.

\subsection{Kriging with external drift and residual kriging}

For both RK and KED, a trend is removed from the data for kriging. The difference is that for RK, trend estimating and kriging are performed independently. The effect of spatial correlation in data is not considered by the RK regression. For KED, the two are performed simultaneously, with the spatial correlation effect being considered. This renders KED statistically more appealing. However, because the trend is estimated automatically in KED, some understanding of physical processes may not be able to be reflected in the trend, and even worse, the trend may not have the support of common sense (Isaaks and Srivastava, 1989, p. 532). In addition, because all data points are included in the KED trend estimating, a few outliers may deviate the estimates from the optimal trend. These issues become less problematic for RK because the trend estimates can be compared and tested before the kriging. In particular, a few outliers (if identified) with respect to the dominant trend can be excluded from the regression for the trend estimates. Thus, in terms of actual performance, KED and RK both have advantages and disadvantages. In fact, when the generalized least squares are 
used to fit the regression, they are shown to be equivalent by Hengl et al. (2007).

In this study, both RK (ordinary least squares being used for regression fitting) and KED are performed and compared. $\mathrm{KED}$ is described below, and RK is explained in the next section. After correlation and partial correlation analysis (Sect. 3.1), it is found that $\log D$ (where $D$ is the BCD value) is better than $D$ to be used to construct the BCD map. Three secondary variables, UTM Easting $X$, Northing $Y$, and elevation $Z$ are selected to estimate the external drift. KED is implemented by jointly fitting the parameters $b_{0}, b_{1}, b_{2}$ and $b_{3}$ in Eq. (4) and the error variogram parameters (sill, nugget, range) of a spherical variogram model, using the Restricted Maximum Likelihood method (Cressie, 1993).

$\log D=b_{0}+b_{1} X+b_{2} Y+b_{3} Z+\varepsilon$

where $\varepsilon$ is the error (or residual) term.

\subsection{ASOADeK regression and mapping}

A residual kriging model, Auto-searched Orographic and Atmospheric effects De-trended Kriging (ASOADeK), is applied to construct the BCD map. The ASOADeK model has two components: a regression to obtain the trend estimates, and a residual kriging to compensate where the regression estimate is poor. The regression was originally developed to auto-search the effects of atmospheric moisture gradient, prevailing moisture flux direction and associated terrain aspect and slope, and terrain elevation, on precipitation distribution. Recently, it was applied to examine orographic effects on rain isotope distribution (Guan et al., 2009). Since wet deposition and dry deposition over the area have similar dominant westerly sources (supported by correlation analysis in Sect. 3.1), we attempt to use the ASOADeK regression to examine the effects of selected geographic (associated with coastal distance) and topographic variables on BCD. The original regression model, including both elevation and terrain aspect, can be found in Guan et al. (2005). The regression model used below including elevation, terrain aspect and slope, first appears in Guan et al. (2009).

$$
\log D=b_{0}+b_{1} X+b_{2} Y+b_{3} Z+b_{4} \beta \cos \alpha+b_{5} \beta \sin \alpha+\varepsilon(5)
$$

where $D$ is BCD $\left(\mathrm{g} \mathrm{m}^{-2} \mathrm{yr}^{-1}\right), X$ and $Y$ are geographic coordinates (usually as easting and northing in UTM coordinate system, in $\mathrm{km}$ ), used to capture the effect of coastal distance dependence, $Z$ is above-sea-level terrain elevation in kilometres, $\beta$ is the slope angle in degree, $\alpha$ is the terrain aspect, defined as the direction of slope orientation, zero to the north, increasing clockwise, and 180 to the south. The two trigonometric terms are derived from $\cos (\alpha-\omega)$, where $\omega$ is the source flux direction. This function has a value of 1 at windward slopes, and -1 at leeward slopes. This formulation was originally designed to capture the orographic effect of more precipitation (or chloride deposition) on the windward slope than on the leeward side. If chloride deposition is enhanced in the leeward side, the sign of $b_{4}$ and $b_{5}$ will be reversed. For situations where the sample size is small, only the terms of statistical significance should be included in the regression. As discussed later, only three predictor variables ( $X, Z$ and $\beta \sin \alpha$ ) are applied for BCD distribution estimates in the study area.

After the regression is performed, it is used to generate a regression estimate map (the trend) based on the digital elevation model (DEM). The difference between the observations and regression estimates are then used to generate a de-trended residual map by ordinary kriging. The final map is the sum of the regression and the residual maps. This procedure is simply called ASOADeK mapping. In this study, the BCD map is obtained by transforming ASOADeK estimated $\log D$ to $D$. The performance of this mapping approach is examined by cross validation, in which each of the total $\mathrm{N}$ data points is set aside each time to compare with the mapping estimate at the location based on the remaining $(N-1)$ data points (Isaaks and Srivastava, 1989). Regression is performed for each cross validation set, while one variogram model is applied for all sets. The mapping result is also compared to direct ordinary kriging of the observed chloride depositions. This is called direct kriging, to be distinguished from KED, and from the residual kriging, which is one component of the ASOADeK model. All kriging calculations (except for KED) are performed with Geostatistical Software Library (Deutsch and Journel, 1998). Finally, the bulk chloride concentration map is then constructed based on the annual chloride deposition map and the annual precipitation map of the study area, both at a spatial resolution of $1 \mathrm{~km} \times 1 \mathrm{~km}$.

After the ASOADeK mapping, the uncertainty originated from the mapping approach is calculated. The mapping uncertainty $\left(\varepsilon_{\mathrm{m}}\right)$ is composed of the regression uncertainty and residual kriging uncertainty. With an assumption that the mapping uncertainty follows normal distribution, it is calculated as

$\varepsilon_{\mathrm{m}}=u \sqrt{\varepsilon_{\mathrm{r}}^{2}+V_{\mathrm{k}}}$

where $u$ is the critical value of the standard normal distribution, (1.645 for $90 \%$, and 1.960 for $95 \%$ confidence level), $\varepsilon_{\mathrm{r}}$ is the standard error of the regression fit, and $V_{\mathrm{k}}$ is kriging variance. A confidence level of $90 \%$ is used in this study. This error is calculated based on $\log D$, which is then converted to $D$ to construct the uncertainty map. Because of nonlinear nature of the exponential function, resulted positive and negative uncertainties (i.e., error bars) are not symmetric. 
Table 2. Pearson correlation coefficients and partial correlation coefficients of chloride deposition $D$ and $\log D$ with selected variables for the data sets of 15 sites and 17 sites. ( $P$ is long-term mean annual precipitation, other symbols are described in Eq. (5), the correlation coefficients in bold face are significant above $99.9 \%$ confidence level for simple correlation, and above $95 \%$ for partial correlation).

\begin{tabular}{|c|c|c|c|c|c|c|c|c|c|c|c|c|}
\hline \multirow{3}{*}{ Variables } & \multicolumn{6}{|c|}{15 data points } & \multicolumn{6}{|c|}{17 data points } \\
\hline & \multicolumn{2}{|c|}{ Simple correlation } & \multicolumn{4}{|c|}{ Partial correlation } & \multicolumn{2}{|c|}{ Simple correlation } & \multicolumn{4}{|c|}{ Partial correlation } \\
\hline & $D$ & $\log D$ & $\begin{array}{r}D \\
(X)\end{array}$ & $\begin{array}{r}\log D \\
(X)\end{array}$ & $\begin{array}{r}\log D \\
(X, Z)\end{array}$ & $\begin{array}{r}\log D \\
(X, Z, \beta \sin \alpha)\end{array}$ & $D$ & $\log D$ & $\begin{array}{r}D \\
(X)\end{array}$ & $\begin{array}{r}\log D \\
(X)\end{array}$ & $\begin{array}{r}\log D \\
(X, Y)\end{array}$ & $\begin{array}{r}\log D \\
(X, Y, Z)\end{array}$ \\
\hline$P$ & 0.48 & 0.63 & 0.27 & 0.59 & 0.26 & 0.32 & 0.56 & 0.66 & 0.11 & 0.31 & 0.57 & 0.27 \\
\hline$X$ & -0.81 & -0.84 & $\mathrm{NaN}$ & $\mathrm{NaN}$ & $\mathrm{NaN}$ & $\mathrm{NaN}$ & -0.79 & -0.80 & $\mathrm{NaN}$ & $\mathrm{NaN}$ & $\mathrm{NaN}$ & $\mathrm{NaN}$ \\
\hline$Y$ & -0.61 & -0.57 & -0.19 & -0.05 & -0.38 & -0.14 & -0.37 & -0.36 & -0.43 & -0.42 & $\mathrm{NaN}$ & $\mathrm{NaN}$ \\
\hline$Z$ & -0.03 & 0.13 & 0.21 & 0.55 & $\mathrm{NaN}$ & $\mathrm{NaN}$ & 0.17 & 0.27 & -0.06 & 0.11 & 0.53 & $\mathrm{NaN}$ \\
\hline$\beta \cos \alpha$ & 0.03 & 0.08 & -0.24 & -0.20 & -0.37 & 0.14 & 0.11 & 0.14 & -0.23 & -0.19 & 0.03 & 0.17 \\
\hline$\beta \sin \alpha$ & -0.43 & -0.45 & 0.49 & 0.55 & 0.56 & $\mathrm{NaN}$ & -0.49 & -0.51 & 0.22 & 0.21 & 0.25 & 0.07 \\
\hline
\end{tabular}

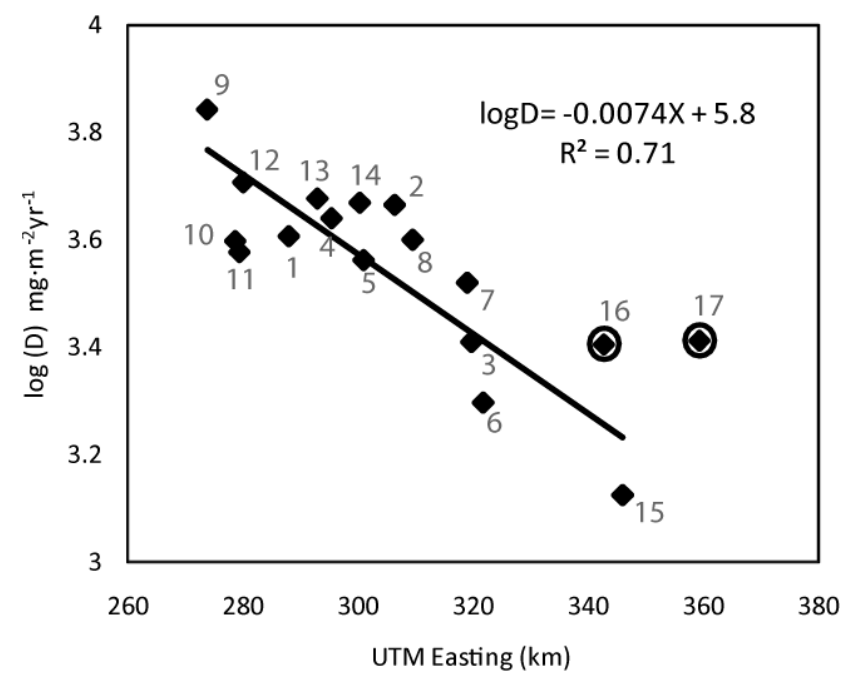

Fig. 3. The log values of observed annual chloride deposition vs. UTM Easting (as a proxy for coastal distance), with sites \#16 and \#17 excluded in the regression. The numbers next to the symbols correspond to those in Table 1 and Fig. 1.

\section{Results}

\subsection{Correlation and regression analysis}

As discussed in Sect. 2.1, the dominant marine chloride source to the study area is from a westerly direction. Chloride deposition data of most sites follows this trend (Table 1, Fig. 3) except for sites 16 and 17. This is most likely because the Southern Ocean chloride source becomes important in BCD at these two sites. To further examine whether $\mathrm{BCD}$ at these two sites behave differently from the other 15 sites, correlation and partial correlation analyses of both $D$ and $\log D$ are conducted with six selected variables (annual precipitation $P$ and the five predictor variables in Eq. 5), for both sets of 15 and 17 sites, respectively (Table 2). As (par- tial) correlation coefficients are slightly larger for $\log D$ than for $D$, further discussion is focused on the $\log D$ results.

For both sets, $X$ is the most significant variable correlated with $\log D$ (Table 2 columns 3 and 9). This result supports our assumption that $X$ closely approximates the coastal distance for BCD in the study area. For the set of 15 data points, after $X$ effect is removed, three significant variables are $P$, $Z$ and $\beta \sin \alpha$ (column 5). Since $P$ and $Z$ are highly correlated (correlation coefficient $=0.95$ ), after $X$ and $Z$ effects are removed, $\beta \sin \alpha$ is the only remaining significant variable (column 6). Thus, for the 15-site set, BCD is influenced by east-west distance, elevation, and terrain aspect. For the set of 17 data points, after the $X$ effect is removed, no significant variable is left (column 11). That $Y$ is not significant for both sets of 15 and 17 data points, with the $X$ effect being removed, supports that the southerly marine chloride source is not important to the study area. If the effects of $X$ and $Y$ are removed, $P$ and $Z$ are the remaining significant variables (column 12). Because of high correlation between $P$ and $Z$, the three most influencing factors are east-west distance, north-south distance, and elevation (column 13). The difference in inferred influencing factors between the two sets of data supports that $\mathrm{BCD}$ at sites 16 and 17 behaves differently from that at the other 15 sites. This result is consistent with our understanding of the BCD in the study area (Sect. 2.1).

Based on the correlation analysis result, three variables $X, Y$, and $Z$ are used to auto-calculate the external drift for KED, because all 17 points have to be included in KED mapping. For RK, ASOADeK model allows regression and residual kriging to be performed separately. Data of either the first 15 sites or the whole 17 points can be used for regression, and then residual data are calculated for the 17 sites for ordinary kriging. To determine which sets of data to be used for ASOADeK regression, regression is performed with corresponding significant variables for each set, respectively (Table 3). The regression based on the first 15 sites outperforms that based on the total 17 sites (Table 3 columns 8-10). 
Table 3. Regression results of $\log D$ with selected variables ( $X, Y$, and $Z$ values are in a unit of $\mathrm{km}$ ) for 15 and 17 points, respectively.

\begin{tabular}{|c|c|c|c|c|c|c|c|c|c|}
\hline & Vari & ples & $b_{0}$ & $b_{1} X$ & $b_{3} Z$ & $b_{5} \beta \sin \alpha$ & $R^{2}$ & Adjusted $^{\mathrm{a}} R^{2}$ & MAE $^{b}$ \\
\hline \multirow{5}{*}{15 data points } & $X$ & $\begin{array}{c}\text { coefficients } \\
\text { p-values }\end{array}$ & $\begin{array}{c}9.59 \\
9 \mathrm{E}-15\end{array}$ & $\begin{array}{l}-1.70 \\
7 \mathrm{E}-05\end{array}$ & & & 0.71 & 0.69 & $0.69(18 \%)$ \\
\hline & \multirow{2}{*}{$X, Z$} & coefficients & 9.43 & -1.82 & 0.84 & & \multirow{2}{*}{0.80} & \multirow{2}{*}{0.77} & \multirow{2}{*}{$0.60(15 \%)$} \\
\hline & & p-values & $2 \mathrm{E}-14$ & $2 \mathrm{E}-05$ & 0.04 & & & & \\
\hline & \multirow{2}{*}{$X, Z, \beta \sin \alpha$} & coefficients & 10.08 & -2.40 & 0.72 & 2.98 & \multirow{2}{*}{0.86} & \multirow{2}{*}{0.83} & \multirow{2}{*}{$0.46(12 \%)$} \\
\hline & & p-values & $1 \mathrm{E}-11$ & $3 \mathrm{E}-05$ & 0.05 & 0.05 & & & \\
\hline & \multicolumn{2}{|c|}{ Predictor variables } & $b_{0}$ & $b_{1} X$ & $b_{2} Y$ & $b_{3} Z$ & $R^{2}$ & Adjusted $R^{2}$ & MAE \\
\hline \multirow{5}{*}{17 data points } & $X$ & $\begin{array}{l}\text { coefficients } \\
\text { p-values }\end{array}$ & $\begin{array}{c}9.25 \\
6 \mathrm{E}-17\end{array}$ & $\begin{array}{l}-1.25 \\
1 \mathrm{E}-04\end{array}$ & & & 0.63 & 0.61 & $0.67(18 \%)$ \\
\hline & \multirow{2}{*}{$X, Y$} & coefficients & 9.61 & -1.2 & 0.004 & & \multirow{2}{*}{0.70} & \multirow{2}{*}{0.66} & \multirow{2}{*}{$0.64(17 \%)$} \\
\hline & & p-values & $1 \mathrm{E}-14$ & 2E-04 & 0.11 & & & & \\
\hline & \multirow{2}{*}{$X, Y, Z$} & coefficients & 9.56 & -0.98 & -0.009 & 0.94 & \multirow{2}{*}{0.78} & \multirow{2}{*}{0.73} & \multirow{2}{*}{$0.60(16 \%)$} \\
\hline & & p-values & $2 \mathrm{E}-14$ & 8E-04 & 0.01 & 0.04 & & & \\
\hline
\end{tabular}

a Adjusted coefficient of multiple determination considering the number of predictor variables effect.

${ }^{\mathrm{b}}$ MAE is the mean absolute error $\left(\mathrm{g} \mathrm{m}^{-2} \mathrm{yr}^{-1}\right)$ of the regression estimates, with percentage of average observation values (3.94 $\mathrm{g} \mathrm{m}^{-2} \mathrm{yr}^{-1}$ for 15 sites, and $3.78 \mathrm{~g} \mathrm{~m}^{-2} \mathrm{yr}^{-1}$ for 17 sites) shown in the brackets.

Thus, sites 16 and 17 are excluded from the ASOADeK regression, but they are included for residual kriging to generate the chloride deposition map.

Both correlation and regression analysis support that BCD at sites 16 and 17 in the southeastern corner, has different influencing factors than the first 15 sites which cover the majority of the study area. To avoid the disturbance from these two sites in examining the dominant BCD influencing processes over the study area, the correlation and regression results based on the first 15 sites are discussed. The regression results indicate that coastal distance explains about $70 \%$ of the $\log D$ spatial variability (Table 3 row 2 ) in the study area, while elevation accounts for about $9 \%$, and terrain aspect and slope accounts for $6 \%$. We now examine the two hypotheses regarding (1) elevation and (2) west-facing slope facilitating chloride deposition. The positive partial correlation result with $X$ effect removed (Table 2 column 5) indicates that elevation enhances chloride deposition. This enhancement is apparently caused by increased precipitation and thus wet chloride deposition with elevation. Terrain aspect and slope are another significant factor on BCD, as indicated by the partial correlation between $D$ and $\beta \sin \alpha$, with $X$ and $Z$ effects removed (Table 2 column 6). The partial correlation coefficient between the two variables is positive. Based on the definition of terrain aspect $\alpha$ in Eq. (5), it has a positive value on east-facing slopes. This indicates that, after the costal distance effect is excluded, more chloride deposition occurs on the eastern slopes (leeward slopes) with respect to the primary atmospheric chloride source direction, instead of on the western (windward) slopes in our starting hypothesis.

\subsection{BCD mapping}

To determine which method is used for BCD mapping, the performance of three methods (direct kriging, KED, and ASOADeK) are compared. Direct kriging is performed with $D$ values based on the 17 sites. Calculated variogram and fitted model is shown in Fig. 4a. KED is performed with $\log D$ values based on the 17 sites, with a fitted variogram model of $($ range $=51 \mathrm{~km}$, sill $=0.028$, nugget $=0.029)$. ASOADeK regression is performed with $\log D$ values based on the first 15 sites. The residual $\log D$ values are then calculated for the 17 sites for ordinary kriging, with calculated variogram and model fitting shown in Fig. 4b. Cross validation is used to evaluate the performance of the three methods (Fig. 5a). The result suggests that $\mathrm{ASOADeK}$ regression, ASOADeK and KED outperform direct kriging. ASOADeK and KED perform similarly, with ASOADeK chosen to construct the final BCD map. The MAE value of ASOADeK regression cross validation is $0.64 \mathrm{~g} \mathrm{~m}^{-2}$, about $16 \%$ of average observation values over the first 15 locations in Table 1 , and the MAE value of ASOADeK cross validation is $0.69 \mathrm{~g} \mathrm{~m}^{-2}$, about $18 \%$ of the observation average. ASOADeK cross validation results slightly degrades in comparison to that of the regression, probably because the chloride network density is too low, resulting in some degree of over-parameterization. The residual kriging is nevertheless applied because sites 16 and 17 are not included in the regression.

Comparison of cross validations provides us confidence to construct BCD map using the ASOADeK model. Both bulk chloride deposition and concentration maps and their uncertainties are shown in Fig. 6. Overall, the annual chloride deposition rate is over $6 \mathrm{~g} \mathrm{~m}^{-2}$ in the southwestern corner and 

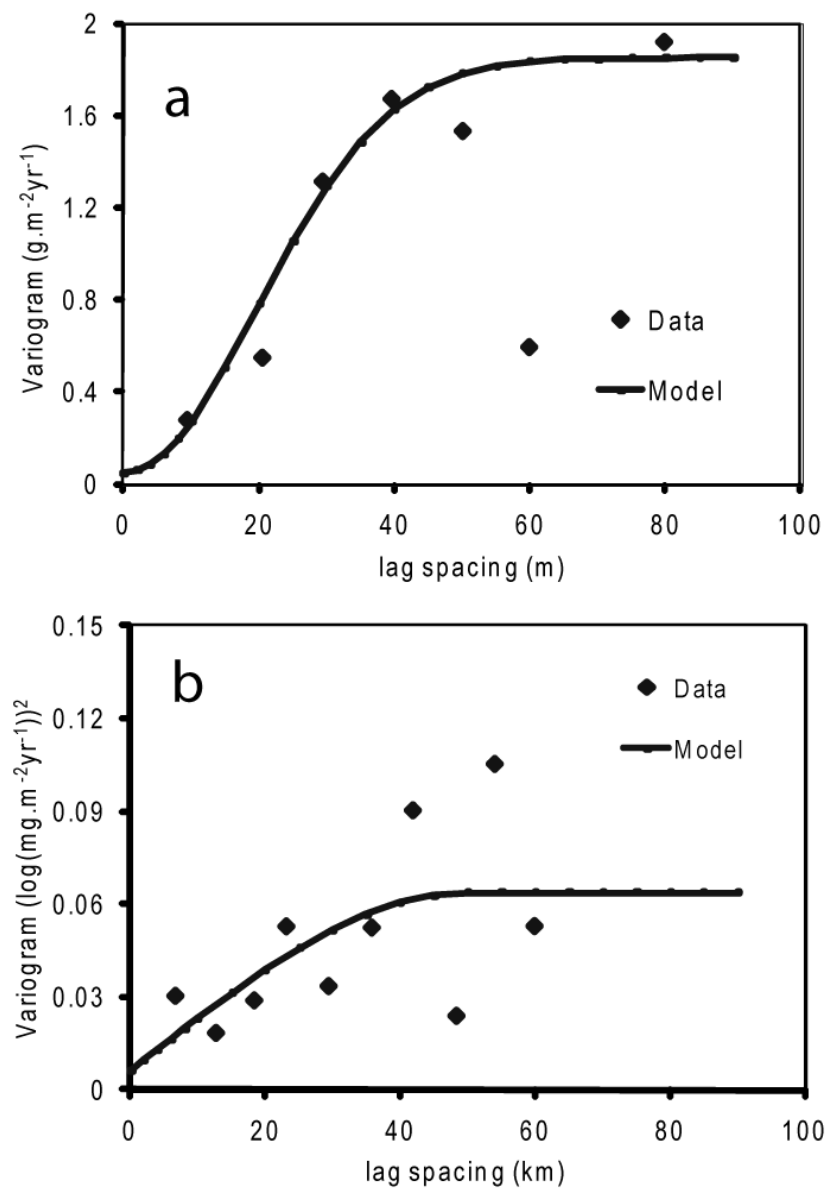

Fig. 4. Calculated variograms and the model fittings for (a) observed annual bulk chloride deposition, and (b) regression detrended $\log D$ residuals over the 17 sites. The fitted model is a Gaussian model $\left(\right.$ range $=48 \mathrm{~km}$, sill $=1.8\left(\mathrm{~g} \mathrm{~m}^{-2}\right)^{2}$, and nugget $\left.=0.05\left(\mathrm{~g} \mathrm{~m}^{-2}\right)^{2}\right)$ for $(\mathrm{a})$, and a spherical model (range $=50 \mathrm{~km}$, sill $=0.058$, and nugget $=0.006$ for $(\mathrm{b})$.

western coast, decreasing to $4-5 \mathrm{~g} \mathrm{~m}^{-2}$ in the central part, and to below $2 \mathrm{~g} \mathrm{~m}^{-2}$ in the eastern and northeastern edges of the area (Fig. 6a). The large uncertainty occurs in the southwestern corner of the study area, which is apparently due to lack of the observation data. When this corner is excluded, the average negative mapping uncertainty at $90 \%$ confidence level is some $1 \mathrm{~g} \mathrm{~m}^{-2}$, about $20 \%$ of the estimated chloride deposition in the western half, while about $40 \%$ for the eastern half of the study area (Fig. 6b). The average positive uncertainty is about $1.5 \mathrm{~g} \mathrm{~m}^{-2}$, about $30 \%$ of estimated chloride deposition in the western half, and $50 \%$ of that in the eastern half of the study area (Fig. 6c). These values are larger than the cross-validation MAE values (Fig. 5a). The mapping uncertainty at the sampling sites is smaller. The mean absolute error of the ASOADeK regression estimates at the 15 sites is $0.45 \mathrm{~g} \mathrm{~m}^{-2}$, equivalent to $11 \%$ of the average observed annual chloride deposition $\left(3.94 \mathrm{~g} \mathrm{~m}^{-2}\right)$ at these sites (Fig. 5b).
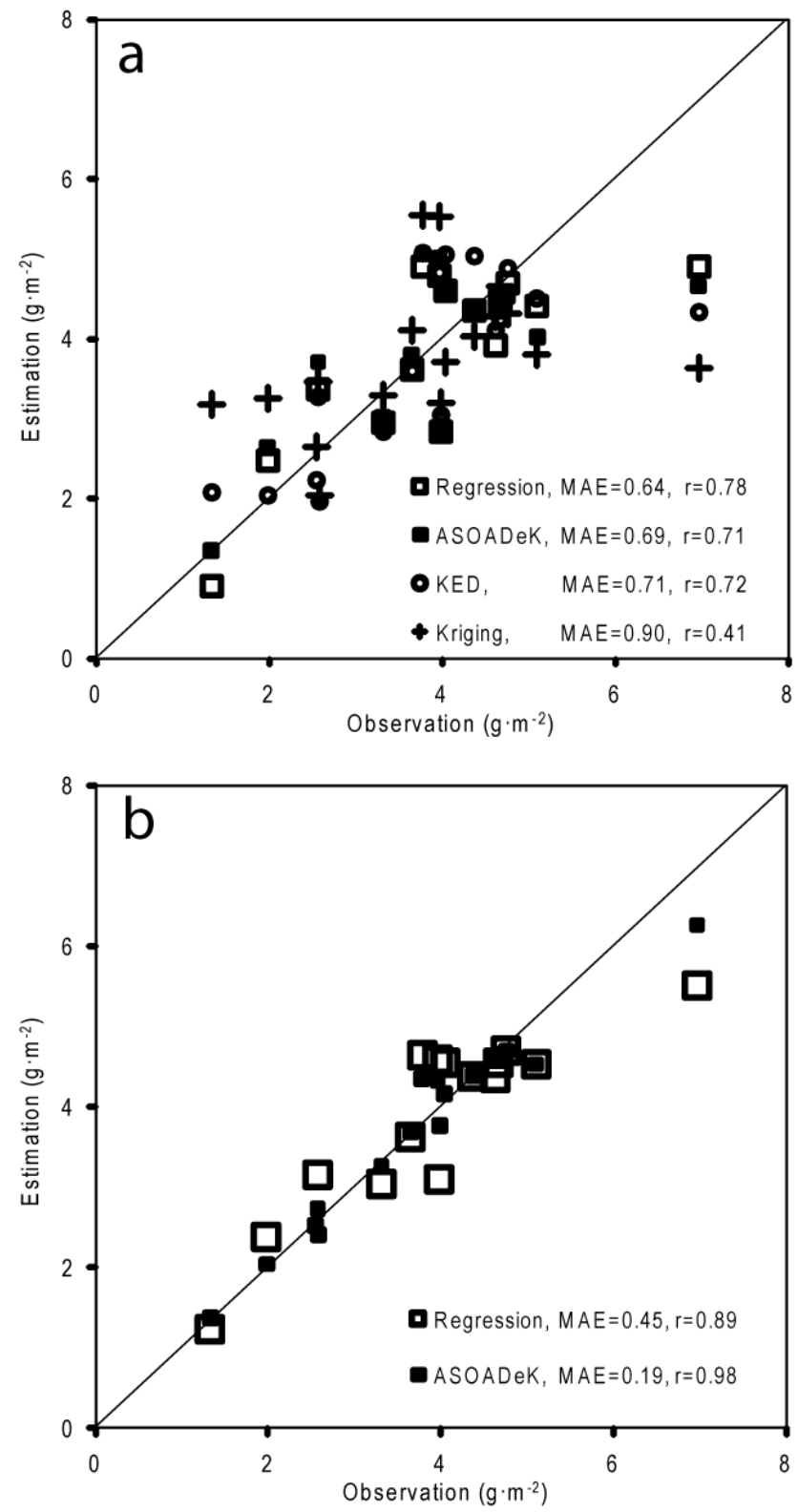

Fig. 5. (a) Cross-validation estimates of annual bulk chloride deposition from regression, ASOADeK, KED, and direct ordinary kriging, and (b) regression estimates of annual bulk chloride deposition (for the 15 sites) and ASOADeK estimates (for all 17 sites), in comparison to the observations. The MAE values are mean absolute errors $\left(\mathrm{g} \mathrm{m}^{-2}\right)$ of the observation sites, and the r-values are Pearson correlation coefficients between the estimates and the observations.

After the residual kriging is added, the mean absolute error over the 17 sites is reduced to $0.19 \mathrm{~g} \mathrm{~m}^{-2}$ (Fig. $5 \mathrm{~b}$, this is different from cross validation results shown in Fig. 5a), about $5 \%$ of the average observed annual deposition at these sites. A long term mean precipitation map was previously constructed for the study area, based on a much denser observation network (96 gauges) and a much longer observation 

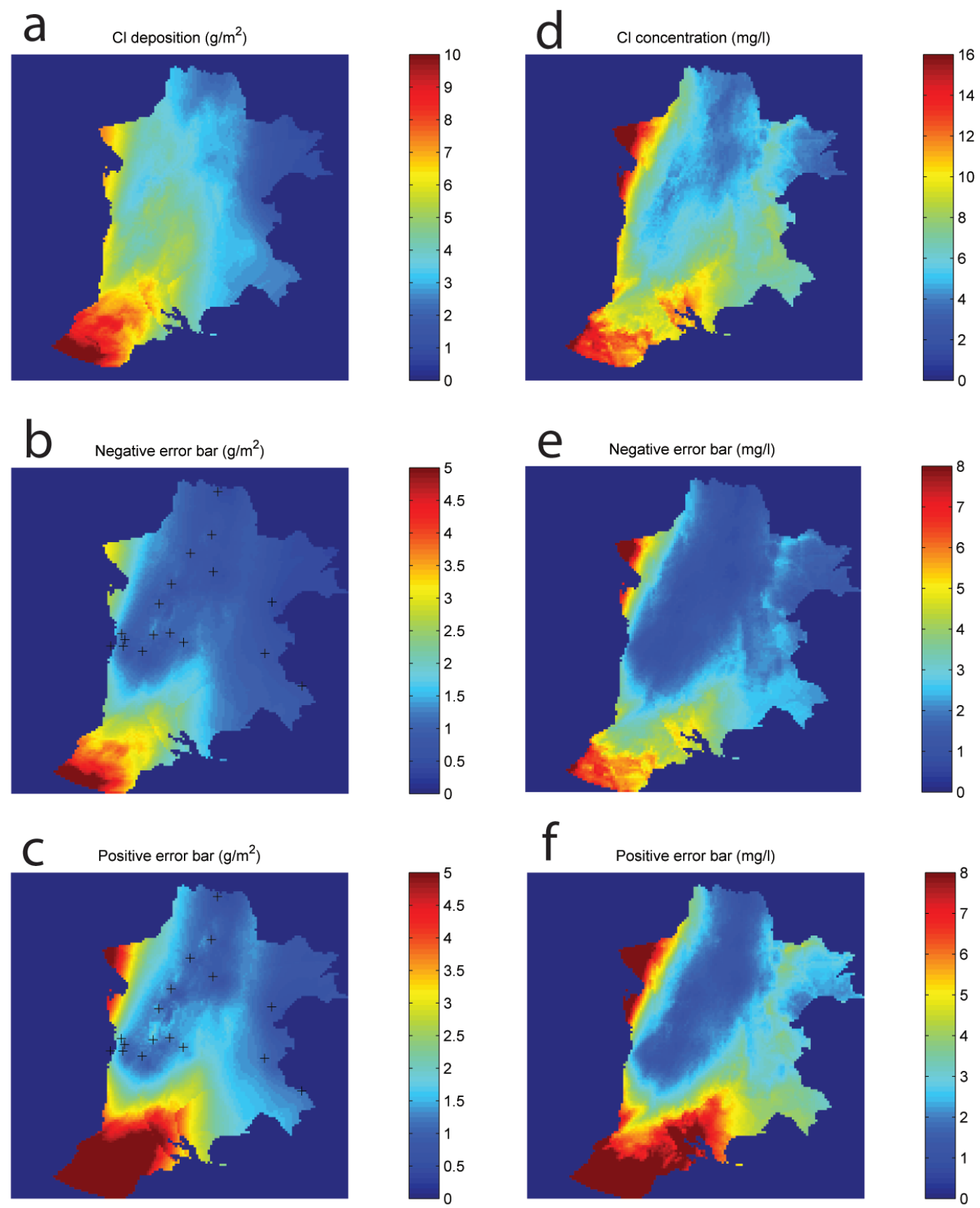

Fig. 6. ASOADeK constructed maps, and their positive and negative uncertainty at a $90 \%$ confidence level, for bulk chloride deposition $\left(\mathrm{g} \mathrm{m}^{-2} \mathrm{yr}^{-1}\right)(\mathbf{a}, \mathbf{b}$, and $\mathbf{c})$, and for bulk chloride concentration $\left(\mathrm{mg} \mathrm{l}^{-1}\right)(\mathbf{d}, \mathbf{e}$, and $\mathbf{f})$. The cross symbols on (b) and (c) is the bulk chloride sampling sites (Fig. 1).

period (the majority of these data have over 30 years records) (Guan et al., 2009). The average uncertainty of the precipitation map is about $2 \%$ at $90 \%$ confidence level. Based on this precipitation map, and the chloride deposition map, a map of bulk chloride concentration (Fig. 6d) and its uncertainty maps (Fig. 6e and f) are provided. The low precipitationmapping uncertainty is neglected when chloride concentration uncertainty is calculated. The map (Fig. 7d) shows that bulk chloride concentration is about $5 \mathrm{mg} \mathrm{l}^{-1}$ in the centre of the MLR, increasing westward toward the coast and southeast ward, to above $10 \mathrm{mg} \mathrm{l}^{-1}$. The uncertainty in bulk chloride concentration is $1-1.5 \mathrm{mg}^{-1}$ for the central of the MLR, below or around $30 \%$ of the estimated chloride concentration. This level of uncertainty is similar to that using more expensive ${ }^{36} \mathrm{Cl} / \mathrm{Cl}$ method (Scanlon, 2000). However, due to the sparse sample points in the eastern part of the study area, 

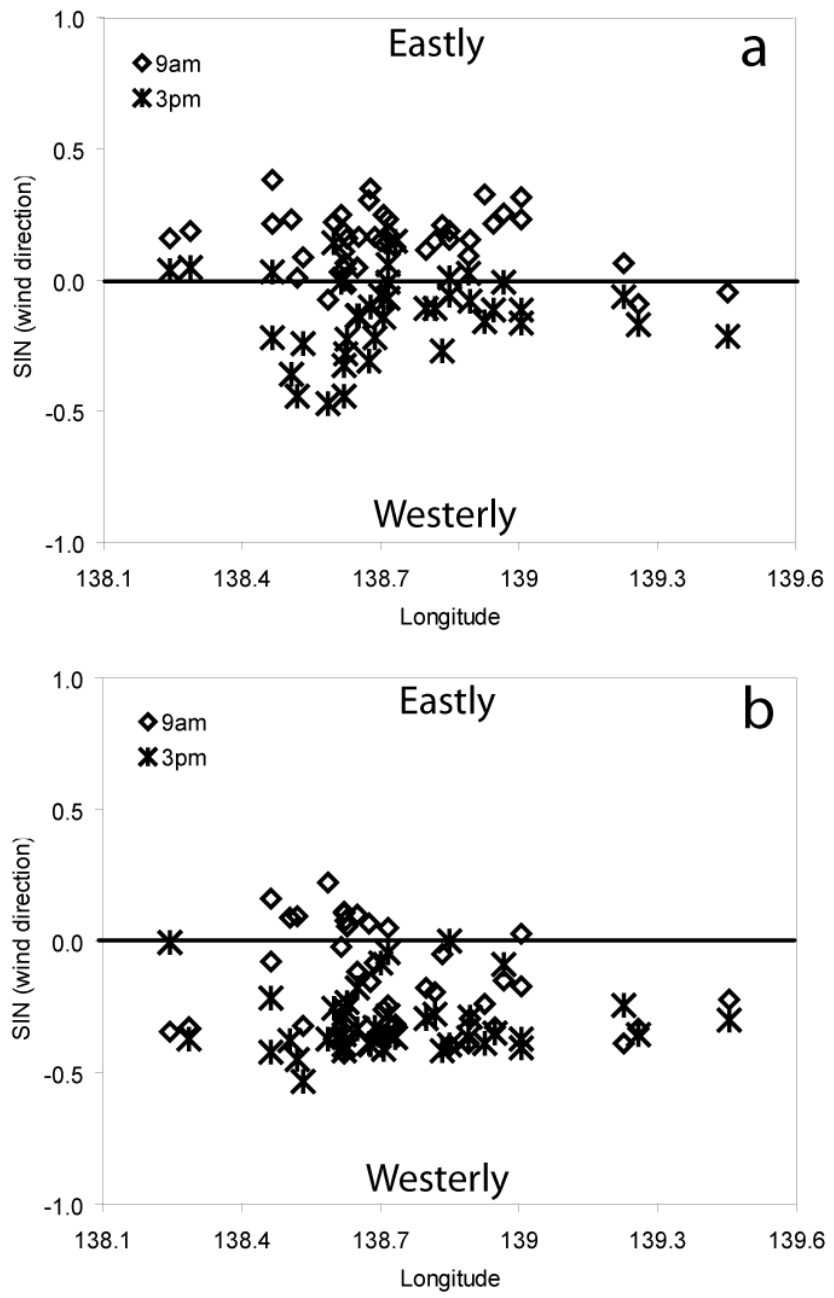

Fig. 7. Mean values of $\sin ($ wind direction) at the 41 observation sites (Fig. 1) for two seasons: (a) summer months (12, 1, 2), and (b) winter months $(6,7,8)$.

the uncertainty is over $40 \%$ of the estimated chloride concentration. More sampling points are recommended for the future in this portion of the area.

\section{Discussion}

It is interesting that chloride deposition in the east-facing slope appears to be significantly larger than the west-facing slope. Previously, we thought that the western slope, facing incoming chloride-bearing aerosols flux, might intercept atmospheric chloride and enhance deposition. This hypothesis is not supported by the correlation analysis result. As wind plays an important role in aerosol transport, analysis of wind direction may give us some hints. In Fig. 7, the average sine values of wind direction at 9:00 a.m. and 3:00 p.m. are plotted against longitude. The sine value is positive if the wind comes from the east, and negative if the wind comes from the west. During the day time (reflected in 3:00 p.m. measurements), westerly winds dominate in the study area, which may facilitate aerosol transport to the east. When the westerly air mass is constrained by the topographic barrier on the western slope, wind speed increases, and reaches the maximum at the upwind side of the hill. The wind speed decreases over the downwind slope. This phenomenon has been extensively studied in sand dune formation processes (Andreotti et al., 2002). The elevated wind speed at the upwind slope facilitates atmospheric chloride transport, and a decreased wind speed at the downwind slope facilitates chloride deposition, which may explain the positive partial correlation between $D$ and $\beta \sin \alpha$ from the data. The above discussion is based on the assumption that the ocean to the west of the study area is the only source of atmospheric chloride. Without further sampling and examination, other possibility cannot be excluded. For example, the positive partial correlation between $D$ and $\beta \sin \alpha$ may be an artefact from local dust recycling, or local atmospheric chloride sources.

\section{Conclusions}

Bulk chloride deposition in Adelaide and the Mount Lofty Ranges, a coastal area in South Australia, was examined with selected geographical (coastal distance), orographic (elevation, slope and aspect), and atmospheric (precipitation) variables. Both partial correlation analysis and regression analysis were performed to understand the controlling factors in bulk chloride deposition. The results support that westerly marine source provides aerosols for BCD in the most part of the study area, and indicate that the coastal distance, elevation, and terrain aspect and slope appear to be three significant factors controlling chloride deposition. Coastal distance accounts for about $70 \%$ of the spatial variability in chloride deposition, with elevation, and terrain aspect and slope accounting for about $15 \%$. Elevation enhances chloride deposition most likely by increasing wet deposition. The correlation results suggest that more chloride deposition occurs at the eastern slope than the western slope of the MLR. Based on the regression analysis results, a de-trended residual kriging mapping procedure (ASOADeK) was applied to construct a bulk chloride deposition map and a bulk chloride concentration map. The average uncertainty of the deposition map is $20-30 \%$ in the western and central MLR, comparable to that of the ${ }^{36} \mathrm{Cl} / \mathrm{Cl}$ method, and over $40 \%$ in the eastern MLR where more future sampling is recommended. The maps will be useful to examine catchment chloride balance for the CMB application in the study area, which is the subject of a separate paper.

Acknowledgements. Discussion with Graham Green and constructive comments from the editor (J. Carrera) and four reviewers (P. Goovaerts, F. J. Alcala, M. Hrachowitz, and R. S. Crossbie) are appreciated. The Department of Water, Land and Biodiversity Conservation of South Australia provided some precipitation 
chloride data, and GIS layers. Bureau of Meteorology provided long-term precipitation data, and wind data. Darren Ray (BOM), Tania Wilson, Graham Green, and Eddie Banks (DWLBC), and Russell Jones (Water Data Services), assisted in data preparation.

Edited by: J. Carrera

\section{References}

Alcala, F. J. and Custodio, E.: Atmospheric chloride deposition in continental Spain, Hydrol. Processes, 22(18), 3636-3650, 2008a.

Alcala, F. J. and Custodio, E.: Using the $\mathrm{Cl} / \mathrm{Br}$ ratio as a tracer to identify the origin of salinity in aquifers in Spain and Portugal, J. Hydrol., 359(1-2), 189-207, 2008b.

Andreotti, B., Claudin, P., and Douady, S.: Selection of dune shapes and velocities - Part 1: Dynamics of sand, wind and barchans, Eur. Phys. J. B, 28(3), 321-339, 2002.

Biggs, A. J. W.: Rainfall salt accessions in the Queensland MurrayDarling Basin, Australian J. Soil Res., 44(6), 637-645, 2006.

Blackburn, G. and McLeod, S.: Salinity of Atmospheric Precipitation in the Murray-Darling Drainage Division, Australia, Australian J. Soil Res., 21, 411-434, 1983.

BOM: Bureau of Meteorology of Australia, www.bom.gov.au, visited 2009.

Carratala, A., Gomez, A., and Bellot, J.: Mapping rain composition in the east of Spain by applying kriging, Water Air and Soil Pollution, 104(1-2), 9-27, 1998.

Chang, Y. H., Scrimshaw, M. D., Emmerson, R. H. C., and Lester, J. N.: Geostatistical analysis of sampling uncertainty at the Tollesbury Managed Retreat site in Blackwater Estuary, Essex, UK: Kriging and cokriging approach to minimise sampling density, Sci. Total Environ., 221(1), 43-57, 1998.

Contreras, S., Boer, M. M., Alcala, F. J., Domingo, F., Garcia, M., Pulido-Bosch, A., and Puigdefabregas, J.: An ecohydrological modelling approach for assessing long-term recharge rates in semiarid karstic landscapes, J. Hydrol., 351(1-2), 42-57, 2008.

Cook, P. G., Edmunds, W. M., and Gaye, C. B.: Estimating paleorecharge and paleoclimate from unsaturated zone profiles, Water Resour. Res., 28(10), 2721-2731, 1992.

Cressie, N.: Statistics for Spatial Data, Wiley, New York, 1993.

Deutsch, C. V. and Journel, A. G.: GSLIB-Geostatistical Software Library and User's Guide. Applied Geostatistics Series, Oxford University Press, New York, 369 pp, 1998.

Dunn, S. M. and Bacon, J. R.: Assessing the value of Cl- and delta O-18 data in modelling the hydrological behaviour of a small upland catchment in northeast Scotland, Hydrol. Res., 39(5-6), 337-358, 2008.

Edmunds, W. M., Fellman, E., Goni, I. B., and Prudhomme, C.: Spatial and temporal distribution of groundwater recharge in northern Nigeria, Hydrogeol. J., 10(1), 205-215, 2002.

Eriksson, E.: The yearly circulation of chloride and sulphur in nature; meteorological, geochemical and pedological implications, part I, Tellus, 11(4), 375-403, 1959.

Eriksson, E.: The yearly circulation of chloride and sulphur in nature; meteorological, geochemical and pedological implications, part II, Tellus, 12, 63-109, 1960.

Eriksson, E. and Khunakasem, V.: Chloride concentrations in groundwater, recharge rate and rate of deposition of chloride in the Israel coastal plain, J. Hydrol., 7, 178-197, 1969.
Friedman, I., Smith, G. I., Gleason, J. D., Warden, A., and Harris, J. M.: Stable isotope composition of waters in southeastern California. 1. Modern precipitation, J. Geophys. Res.-Atmos., 97(D5), 5795-5812, 1992.

Goncalves, F. L. T., Andrade, M. F., Forti, M. C., Astolfo, R., Ramos, M. A., Massambani, O., and Melfi, A. J.: Preliminary estimation of the rainfall chemical composition evaluated through the scavenging modeling for north-eastern Amazonian region (Amapa State, Brazil), Environ. Pollut., 121(1), 63-73, 2003.

Goovaerts, P.: Geostatistical approaches for incorporating elevation into the spatial interpolation of rainfall, J. Hydrol., 228(1-2), 113-129, 2000.

Guan, H., Simmons, C. T., and Love, A. J.: Orographic controls on rain water isotope distribution in the Mount Lofty Ranges of South Australia, J. Hydrol., 374(3-4), 255-264, 2009.

Guan, H., Wilson, J. L., and Makhnin, O.: Geostatistical mapping of mountain precipitation incorporating autosearched effects of terrain and climatic characteristics, J. Hydrometeorol., 6(6), 10181031, 2005.

Gustafsson, M. E. R. and Larsson, E. H.: Spatial and temporal patterns of chloride deposition in Southern Sweden, Water Air Soil Pollut., 124(3-4), 345-369, 2000.

Hengl, T., Heuvelink, G. B. M., Rossiter, D. G.: About regressionkriging: From equations to case studies, Comput. Geosci., 33, 1301-1315, 2007

Hrachowitz, M., Soulsby, C., Tetzlaff, D., Dawson, J. J. C., and Malcolm, I. A.: Regionalization of transit time estimates in montane catchments by integrating landscape controls, Water Resour. Res., 45, W05421, 2009.

Isaaks, E. H. and Srivastava, R. M.: Applied Geostatistics. Oxford Unviersity Press, Inc, 561 pp, 1989.

Kayaalp, A. S.: Application of rainfall chemistry and isotope data to hydro-meteorological modelling, $\mathrm{PhD}$ Thesis, Flinders University, Adelaide, Australia, 273 pp, 2001.

Keywood, M. D., Chivas, A. R., Fifield, L. K., Cresswell, R. G., and Ayers, G. P.: The accession of chloride to the western half of the Australian continent, Australian J. Soil Res., 35(5), 1177-1189, 1997.

Kirchner, J. W., Feng, X. H., and Neal, C.: Fractal stream chemistry and its implications for contaminant transport in catchments, $\mathrm{Na}-$ ture, 403(6769), 524-527, 2000.

Lewis, E. R. and Schwartz, S. E.: Sea Salt Aerosol Production: Mechanisms, Methods, Measurements and Models - A Critical Review. Geophysical Monograph 152. American Geophysical Union, Washington, D.C., 413 pp, 2004.

Lowry, R.: Concepts and Applications of Inferential Statistics, http: //faculty.vassar.edu/lowry/webtext.html, Vassar College, Poughkeepsie, NY USA, 1999-2009.

Minor, T. B., Russell, C. E., and Mizell, S. A.: Development of a GIS-based model for extrapolating mesoscale groundwater recharge estimates using integrated geospatial data sets, Hydrogeol. J., 15(1), 183-195, 2007.

Phillips, F. M.: Environmental tracers for water movement in desert soils of the American southwest, Soil Sci. Soc. Am. J., 58(1), 15-24, 1994.

Preiss, W. V.: The Adelaide Geosyncline: Late proterozoic stratigraphy, sedimentation, palaeontology and tectonics, Bulletin/Geological Survey of South Australia, 53, 439, 1987.

Scanlon, B. R.: Uncertainties in estimating water fluxes and resi- 
dence times using environmental tracers in an arid unsaturated zone, Water Resour. Res., 36(2), 395-409, 2000.

Scanlon, B. R., Healy, R. W., and Cook, P. G.: Choosing appropriate techniques for quantifying groundwater recharge, Hydrogeol. J., 10(1), 18-39, 2002.

Shaw, S. B., Harpold, A. A., Taylor, J. C., and Walter, M. T.: Investigating a high resolution, stream chloride time series from the Biscuit Brook catchment, Catskills, NY, J. Hydrol., 348(3-4), 245-256, 2008.

Walker, G. R., Jolly, I. D., and Cook, P. G.: A new chloride leaching approach to the estimation of diffuse recharge following a change in land use, J. Hydrol., 128, 49-67, 1991.
Wilson, J. L. and Guan, H.: Mountain-block hydrology and mountain-front recharge, in: Groundwater Recharge in a Desert Environment: The Southwestern United States, edited by: Hogan, J. F., Phillips, F. M., and Scanlon, B. R., Water Science and Applications Series. American Geophysical Union, Washington, D.C., pp. 113-137, 2004.

Wood, W. W. and Sanford, W. E.: Chemical and isotopic methods for quantifying groundwater recharge in a regional, semiarid environment, Ground Water, 33(3), 458-468, 1995.

Wood, W. W.: Use and misuse of the chloride-mass balance method in estimating ground water recharge, Ground Water, 37(1), 2-3, 1999. 